\title{
Oral atenolol treatment for infantile hemangiomas: clinical analysis of 133 consecutive patients
}

\author{
Ze-Liang Zhao ${ }^{1 \#}$, Chao Liu ${ }^{1 \#}$, Qi-Zhang Wang ${ }^{1}$, Hai-Wei Wu ${ }^{2}$, Jia-Wei Zheng ${ }^{1}$ \\ ${ }^{1}$ Department of Oromaxillofacial Head and Neck Oncology, Shanghai Ninth People's Hospital, College of Stomatology, Shanghai Jiao Tong \\ University School of Medicine, Shanghai, China; ${ }^{2}$ Department of Oral and Maxillofacial Surgery, Shandong Provincial Hospital Affiliated to \\ Shandong University, Jinan, China \\ Contributions: (I) Conception and design: JW Zheng; (II) Administrative support: JW Zheng; (III) Provision of study materials or patients: ZL Zhao, \\ C Liu; (IV) Collection and assembly of data: ZL Zhao, C Liu, QZ Wang, HW Wu; (V) Data analysis and interpretation: ZL Zhao, C Liu; (VI) \\ Manuscript writing: All authors; (VII) Final approval of manuscript: All authors. \\ \#These authors contributed equally to this work. \\ Correspondence to: Jia-Wei Zheng. Department of Oromaxillofacial Head and Neck Oncology, Shanghai Ninth People's Hospital, College of \\ Stomatology, Shanghai Jiao Tong University School of Medicine, 639 Zhizaoju Road, Shanghai 200011, China. Email: davidzhengjw@hotmail.com.
}

Background: Infantile hemangiomas (IHs) are the most frequently occurring pediatric lesions. Oral propranolol has been shown to be safe and effective in infants with IHs. Side effects such as sleep disturbances have been associated with propranolol. Atenolol is a hydrophilic, selective $\beta 1$-blocker and therefore may be not associated with side effects attributable to $\beta 2$-adrenergic receptor blockade and lipophilicity. However, the efficacy of atenolol in the treatment of IHs is poorly understood. The aim of this study was to evaluate the efficacy of atenolol in the treatment of proliferating IHs in a clinical cohort including 133 consecutive patients.

Methods: In this study, we enrolled 133 patients diagnosed as proliferating IHs from the routine clinical and referral practices of the authors. The procedures followed were in accordance with the ethical standards of the Institute Review Board of Shanghai Ninth People's Hospital and Helsinki Declaration. Clinical characteristics, including demographic data and clinical morphology, were collated. Responses to oral atenolol therapy were graded as: excellent, good, fair and poor. According to the reaction to atenolol treatment, additional medications or therapy were used for IH patients to achieve satisfactory clinical results. Results: In this study, 128 (96.2\%) of $133 \mathrm{IH}$ patients responded to oral atenolol, and the response rate (RR) was significantly different for different ages of patients $(\mathrm{P}<0.05)$, with the youngest patients having the highest RR. The mean time of treatment was 4.9 months. Forty-one patients who exhibited residual hyperpigmentation or telangiectasia were further treated with timolol maleate cream $(n=32)$ or pulsed dye laser $(n=9)$. All the 41 patients showed positive response. No life-threatening complications were noted during and after oral atenolol. Only 4 (3.0\%) of 133 patients developed minor complications including diarrhea. No agitation and bronchospasm were noted in our study.

Conclusions: This study demonstrated that atenolol was effective in the treatment of IHs. Compared to propranolol, atenolol seems to have a similar effect on IHs. Furthermore, atenolol seems to be less frequently associated with potentially life-threatening side effects.

Keywords: Atenolol; infantile hemangioma (IH); $\beta$-blockers; intervention studies

Submitted Jul 16, 2020. Accepted for publication Sep 30, 2020.

doi: $10.21037 /$ atm-20-5359

View this article at: http://dx.doi.org/10.21037/atm-20-5359 


\section{Introduction}

Infantile hemangiomas (IHs), which ensue from endothelial cell (EC) hyperplasia, are the most common soft tissue tumors of infancy (1). IHs occur in $3 \%$ to $10 \%$ of infants. Higher risk is associated with several well-known factors, including low birth weight, female predominance, prematurity and multiple gestation (2). IHs arise in the first few weeks after birth, then display an active growth period followed by spontaneous involution. The characteristic evolution of nearly all IHs is proliferation, stabilization, and slow, spontaneous involution (3). For decades, treatment of IHs has mainly been focused on corticosteroids or surgery. Since 2008, numerous publications have shown the efficacy of oral propranolol for the treatment of His (4-6). Because propranolol is a highly lipophilic $\beta$-blocker and thus capable of crossing the blood-brain barrier (BBB), there is a theoretical probability of the central nervous system being affected by propranolol (7) (that is, impairment of short- and long-term memory, psychomotor function, sleep quality, and mood). Although these side effects are usually well tolerated, some patients must discontinue treatment. On the other hand, atenolol, a hydrophilic cardioselective $\beta$-blocker that acts principally on $\beta 1$ receptors, does not cross the BBB and has fewer $\beta 2$ effects (8). More recently, atenolol has been studied as an effective and safe systemic $\beta$-blocker for treatment of His (9-11). Early intervention can make the risk of development of potential complications to a minimum during the proliferative stage of IHs. In this study, we present our experience in the treatment of IHs with oral atenolol as a first-choice therapy in 133 consecutive patients. We present the following article in accordance with the STROBE reporting checklist (available at http://dx.doi.org/10.21037/atm-20-5359).

\section{Methods}

\section{Study design}

In this study, 133 patients diagnosed as proliferating IHs at the Department of Oromaxillofacial Head and Neck Surgery, Shanghai Ninth People's Hospital were enrolled from January 2015 to December 2017. The procedures followed were in accordance with the ethical standards of the Institute Review Board of Shanghai Ninth People's Hospital (SH9H-2019-T272-1) and Helsinki Declaration (as revised in 2013). The Institutional Review Board of Shanghai Ninth People's Hospital approved this study. Written informed consents were obtained from all parents of the patients. Informed consent was obtained from the guardians of the patients whose images were presented in the study. Data collected for each patient included demographic characteristics, type of IHs (superficial, deep, or compound), duration of treatment, initial treatment age, reported adverse effects, and response rate (RR) to atenolol.

\section{Treatment regimen}

Prior to treatment, the patients were screened for contraindications and an echocardiography was performed to detect any possible congenital heart defects such as atrioventricular block or bradycardia. All patients received oral atenolol (atenolol tablet, The Central Pharmaceutical Co., Ltd., Tianjin Municipality, China) in an outpatient setting and no patient required hospitalization during the study for initiation of treatment. During the treatment, atenolol dosage was adjusted according to body weight. Atenolol was administered in the morning and late afternoon, 30 minutes after feeding. The initial dosage of atenolol was $0.5 \mathrm{mg} / \mathrm{kg} / \mathrm{day}$. After 1 week of treatment, atenolol dosage was increased to $1 \mathrm{mg} / \mathrm{kg} / \mathrm{day}$. The dosage was adjusted every month as the increase in weight. In the last month of treatment, the therapy was discontinued based on the clinical responses. The administration of oral atenolol was tapered by decreasing to one-half dose for 2 weeks. If no rebound occurred, the dose was decreased to one-quarter dosage in the following 2 weeks, and then discontinued.

\section{Subsequent therapy}

For patients with minor tumor reduction after treatment with atenolol for 3 months, oral prednisone was administered at a dose of $2 \mathrm{mg} / \mathrm{kg} /$ day every 2 days. If the patients were nonresponsive to atenolol and prednisone, bleomycin was injected into lesions at a dose of $1 \mathrm{mg}$ for 1 to 3 sessions. For patients with residual hyperpigmentation or telangiectasia after oral atenolol, the IH surface was smeared with $0.5 \%$ timolol maleate cream topically three times a day. If the patients were nonresponsive to 1-month treatment of timolol maleate cream, pulsed dye laser was applied at a wavelength of $595 \mathrm{~nm}$ and at a pulse duration of $10 \mathrm{~ms}$.

\section{Outcome measurement}

All hemangiomas underwent ultrasonographic examination 


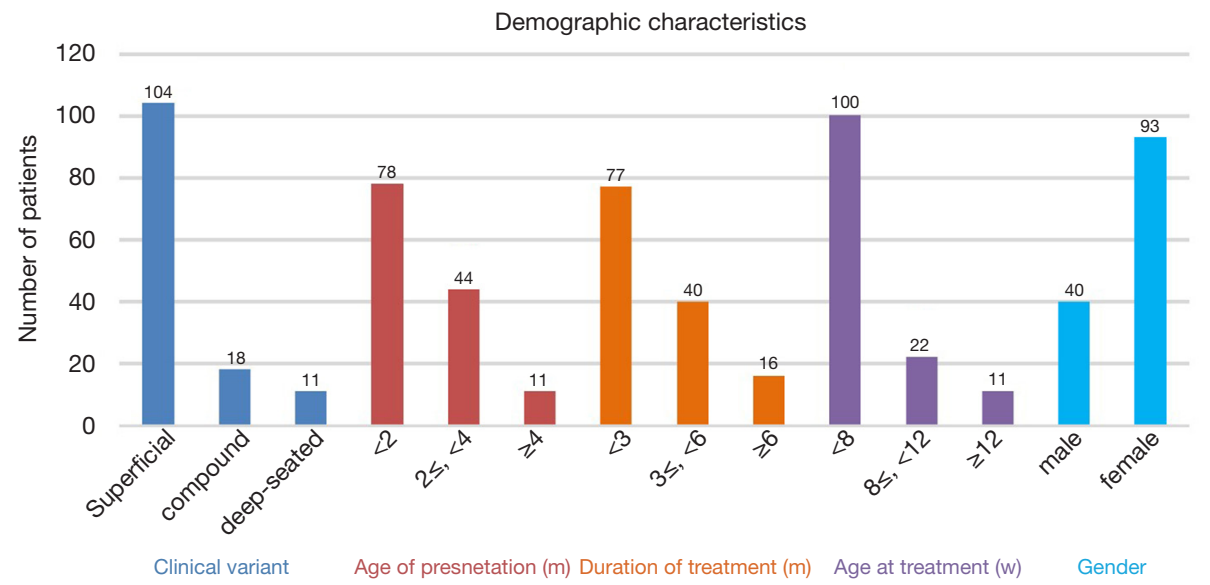

Figure 1 Clinical characteristics of patients.

and were photographed at each visit to evaluate the therapeutic efficacy. Ultrasound examination was adopted to quantify the volume of IH. The volume of IH was defined as previously described (12). Both photographs and ultrasound scan were carried out at 2, 4, and 8 weeks following treatment and at each follow-up. Volume change of IHs could be evaluated under direct vision using photographs, and ultrasound scan provided the quantitative data for analysis. Responses to oral atenolol therapy was graded as poor ( 0 and $<40 \%$ ), fair $(\geq 40 \%$ and $<60 \%)$, good $(\geq 60 \%$ and $<80 \%$ ) and excellent $(\geq 80 \%)$.

\section{Statistical analysis}

Analysis was performed using SPSS software package (version 26.0; SPSS, Chicago, IL, USA). RR to atenolol was summarized according to patient demographic or disease characteristics using analysis of paired $t$-test. $\mathrm{P}<0.05$ was considered to be significant difference.

\section{Results}

\section{Clinical features}

The mean age of 133 patients was $6.17 \pm 4.84$ (range: $1-25$, median: 5) months. The average age at the appearance of IHs was $1.99 \pm 1.29$ weeks. The mean age at treatment initiation was $4.91 \pm 3.73$ weeks. The average treatment duration was $5.39 \pm 3.35$ months (Figure 1). There was a female predominance with a ratio of $2.3: 1$. Nineteen $(14.3 \%)$ of 133 patients were preterm infant, and the most commonly used tocolytic agent was progestin for the treatment of premonitory abortion during pregnancy. The primary locations included trunk $(28,21.1 \%)$, extremities $(23,17.3 \%)$, head and neck region $(82,61.7 \%)$ including cheek(23, 17.3\%), scalp $(14,10.5 \%)$, forehead $(13,9.8 \%)$, parotid gland (9,6.8\%), lip (8, 6.0\%), neck $(8,6.0 \%)$ and nose $(7,5.3 \%)$ (Figure 2). The mean size of hemangioma was $16.56 \pm 11.73 \mathrm{~cm}^{2}$. Of the 133 cases, $104(78.2 \%)$ cases were superficial, 11 (8.3\%) were deep-seated, and 18 (13.5\%) were compound.

\section{Therapeutic outcomes}

Statistical analysis showed significant differences in RR for different age groups of patients, with the youngest patients having the highest $\mathrm{RR}(\mathrm{P}<0.05, t$-test $) . \mathrm{RR}$ to atenolol of the group younger than 8 weeks was $97.8 \%$ (Figure 3), compared with $93.1 \%$ for patients older than 8 weeks and younger than 12 weeks (Figure 4), and $81.4 \%$ for patients older than 12 weeks (Figure 5). Gender had no significant impact on RR to atenolol between different age groups. There was no significant difference of RR to atenolol between different types of IHs (for superficial, deep-seated, or compound hemangiomas, RR: $96.1 \%, 92.8 \%$ vs. $88.5 \%$, $\mathrm{P}>0.05)$. Additionally, as to the location of IHs, there was highest RR when IHs were located in the cheek and lowest $\mathrm{RR}$ in the neck (RR: 98.1\%, 84.2\%, $\mathrm{P}<0.05)$. Moreover, $\mathrm{RR}$ to atenolol was subdivided as follows: excellent in $47(35.3 \%)$ patients, good in $64(48.1 \%)$ patients, fair in $17(12.8 \%)$ patients, and poor in $5(3.8 \%)$ patients. The average period of oral atenolol treatment was $5.39 \pm$ 3.35 (range, 2-15) months (Figure 1). During the outpatient follow-up, complain of diarrhea was recorded in $4(3.0 \%)$ 


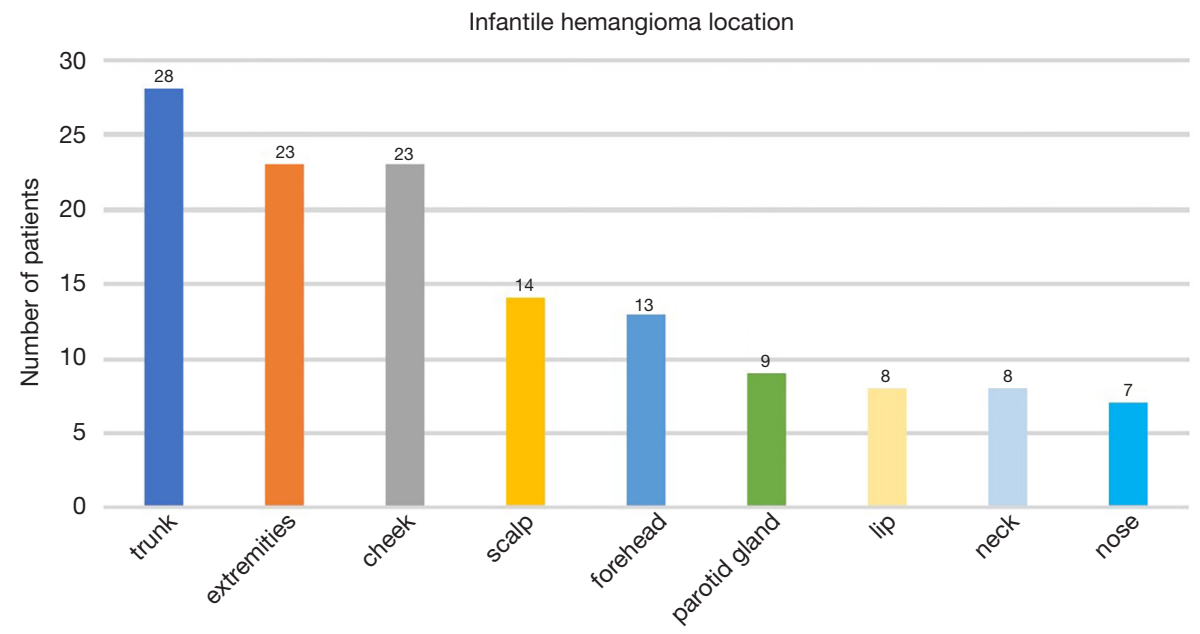

Figure 2 The location of IHs in this study. IH, infantile hemangioma.
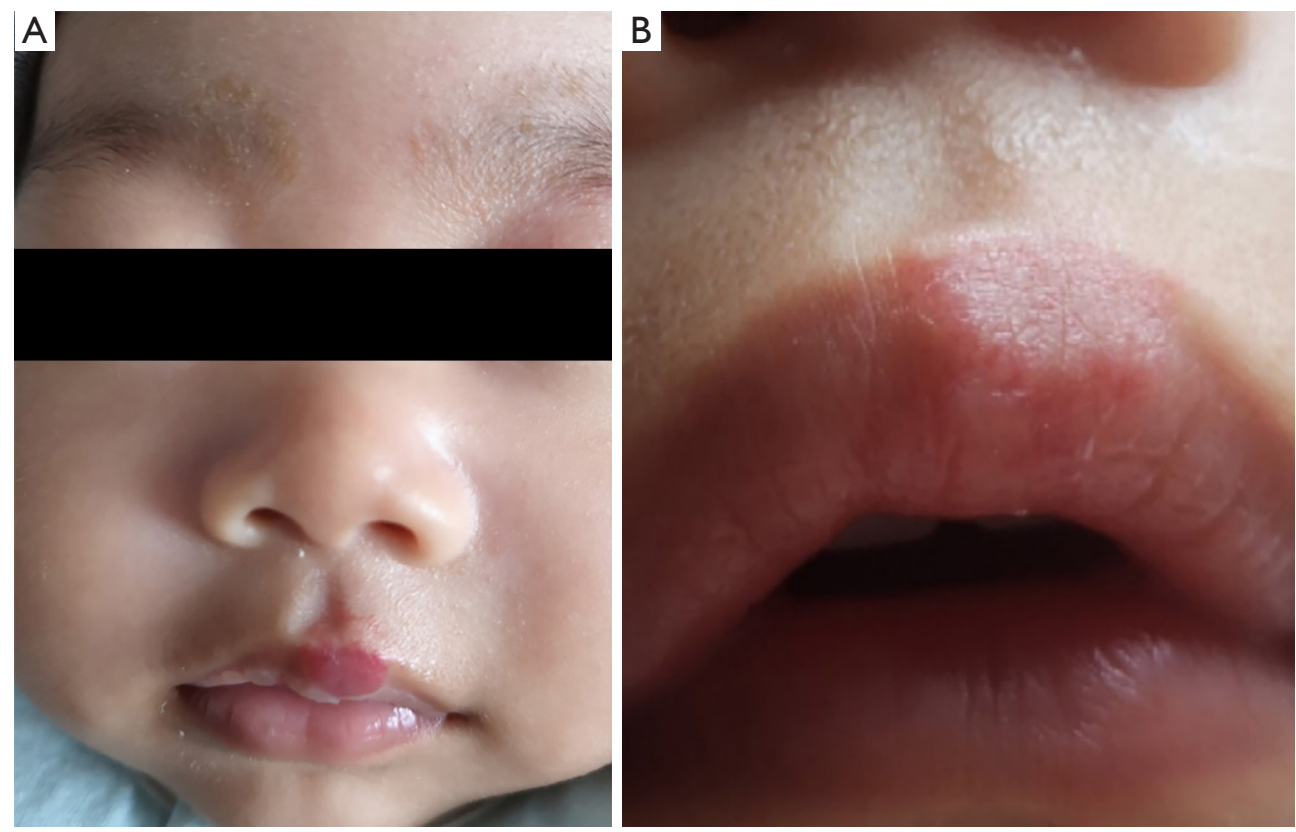

Figure 3 Response of superficial IHs in the upper lip to oral atenolol. (A) Before starting oral atenolol therapy, at the age of 2 months; (B) at the age of 14 months after oral atenolol therapy; obvious discoloration was noted. IH, infantile hemangioma.

of 133 patients. No patients discontinued treatment due to the side effects. No sleep disturbance, somnolence, and bronchospasm were noted. In summary, no patients in our study suffered from major medical complications.

\section{Patient response to subsequent therapy}

For patients with fair response to oral atenolol (17 patients), oral prednisone was added to the treatment regimen. After oral prednisone, 15 (88.2\%) IHs in the 17 patients involuted without recurrence, and one patient was not responsive to oral glucocorticoid. The one nonresponsive patient and five poor-responsive patients were then treated with bleomycin injection. No recurrence was observed in the six cases, and the clinical results of the six patients were satisfactory. After oral atenolol treatment, 41 patients exhibited residual 

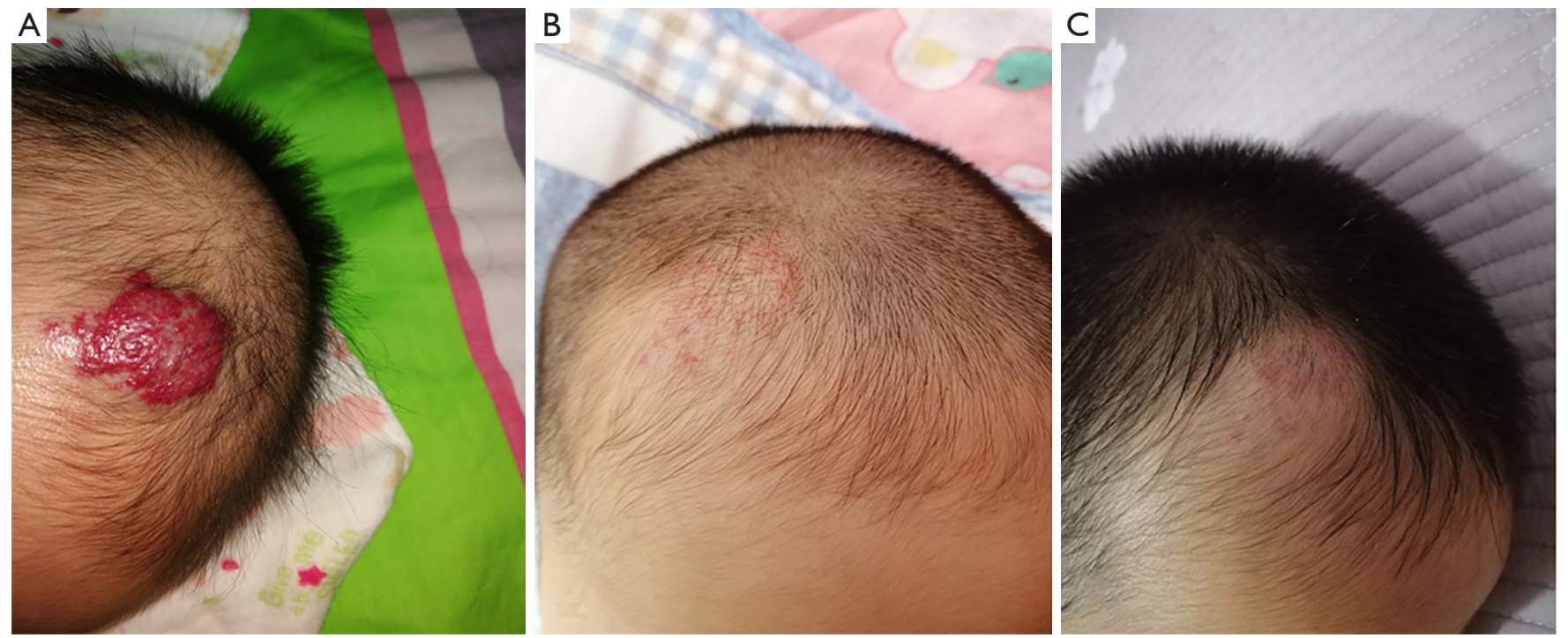

Figure 4 Response of compound IH on the scalp to oral atenolol. (A) A 3-month-old male patient had a large compound hemangioma located on his scalp; (B) obvious volume reduction and discoloration were noted after 11-month treatment of oral atenolol; (C) at the age of 17 months after end of topical timolol therapy; obvious discoloration was noted. IH, infantile hemangioma.
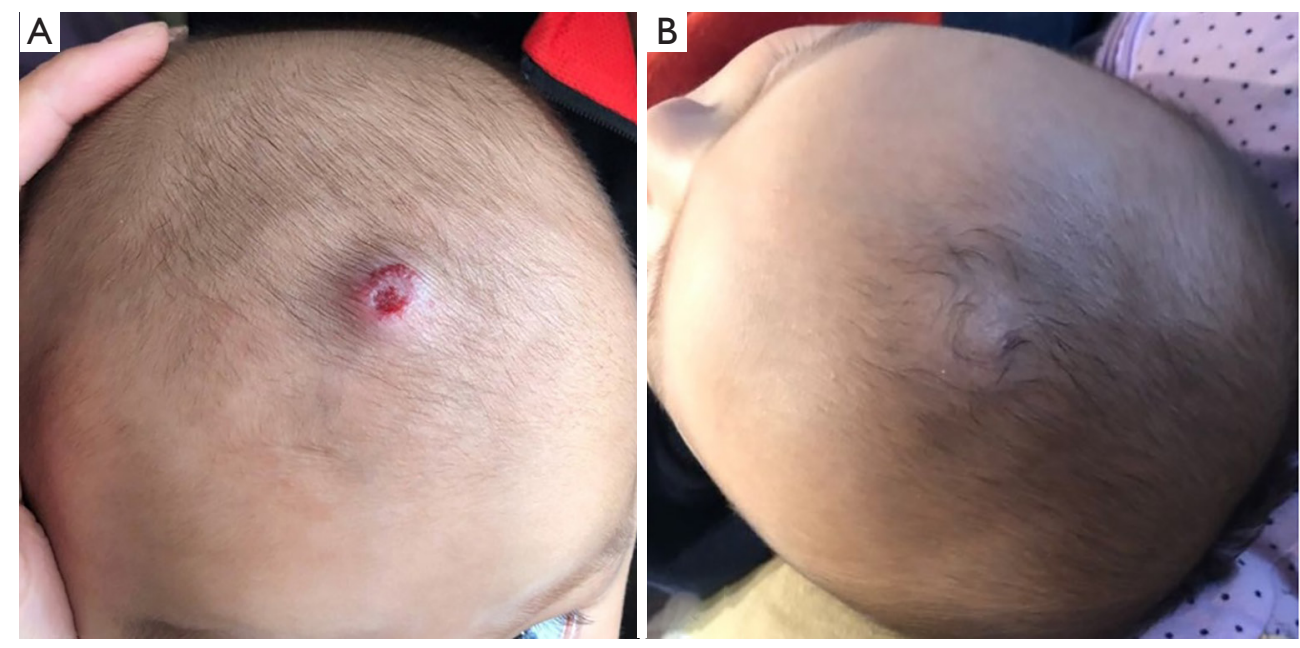

Figure 5 Response of superficial IH on the scalp to oral atenolol. (A) A 3-month-old female patient had a hemangioma located on her scalp which showed ulceration on its surface; (B) the hemangioma significantly regressed after 4-month treatment of oral atenolol. IH, infantile hemangioma.

hyperpigmentation or telangiectasia. Thirty-two patients were administered timolol maleate cream (Figure 4) and 9 patients who were nonresponsive to 1 -month treatment of timolol maleate cream underwent pulsed dye laser irradiation. All the 41 patients showed positive response.

No severe systemic complications were noted in our study. Only 4 (3.0\%) of 133 patients developed minor complications including diarrhea. No agitation and bronchospasm were noted in this case series. The average follow-up period was $2.86 \pm 0.92$ years (Figures $3-5)$. In the groups of excellent (47 patients) and good (64 patients) RR to atenolol, recurrence of IHs were observed in 3 (2.7\%) of 
111 patients. After receiving additional atenolol treatment for fewer than 4 months, all the recurring IHs faded away.

\section{Discussion}

In the past decade, the introduction of oral propranolol for treating IHs has been revolutionary. This $\beta$-blocker has a safer drug profile than long-lasting systemic corticosteroids (13). Studies conducted to compare oral atenolol with oral propranolol for treating IHs showed atenolol was as effective as propranolol $(11,14)$. Atenolol is a synthetic, $\beta 1$-selective (cardio-selective) adrenoreceptor blocking agent and is lipid insoluble hydrophilic compounds. Potential benefits of atenolol over propranolol include its inability to cross the BBB, which may lead to less sleep disturbance and irritability and perhaps theoretically fewer impacts on neurodevelopment/emotional memory. Recently a meta-analysis including 1,175 patients with IHs treated with propranolol demonstrated that the most frequent side effect was sleep disturbances, including nightmares $(3.7 \%)(15)$. In this study, 4 patients $(3.0 \%)$ suffered from gastrointestinal reactions such as diarrhea after initiating atenolol, which was well tolerated in the 4 patients and required no treatment discontinuation. No sleep disturbance, somnolence was complained by the parents of patients. To our knowledge, this is the largest case series to date to evaluate the clinical efficacy of oral atenolol for the treatment of IHs. Compared with our previous described cohort treated with oral propranolol (12), oral atenolol shows fewer central nervous system effects, which is in accordance with another retrospective study (14). No bronchospasm was observed in our study, which was in alignment with the conclusion that hydrophilic $\beta 1$ blocker reduced $\beta 2$ receptor blockade and then decreased the risk of pulmonary side effects (16).

Typically, few side effects are reported in patients receiving $\beta$-blockers for IHs. The clinical efficacy of oral atenolol in this series of $133 \mathrm{IH}$ patients was exciting, with few relapses and good RR, and insignificant adverse events. Twenty-two patients undergoing subsequent therapy achieved satisfactory therapeutic effect. After oral atenolol treatment, forty-one patients exhibiting residual hyperpigmentation or telangiectasia were administered timolol maleate cream or pulsed dye laser and achieved good results. Timolol is a $\beta$-blocker, which is used topically in eye drops to reduce raised intra-ocular pressure and now plays an important role in the treatment of superficial IHs as an off-label agent (17-19). Topical timolol treatment provided an effective supplement to systemic atenolol therapy without any systemic toxicities. The ability to use a less frequent dosing interval with atenolol versus propranolol attributes to differences in the pharmacokinetics and metabolism properties of the two drugs: propranolol has a half-life of 3-6 hours (20), compared with atenolol's half-life of 6-9 hours (21), which may be beneficial to improve patient compliance. However, further studies are needed for the preferred age to initiate treatment of IHs, the optimal dosage, duration of treatment and the criteria for discontinuing treatment.

Theoretically, $\beta$-blockers have some similar potential mechanisms of action on IHs. $\beta$-blockers produce a therapeutic vasoconstrictive effect due to inhibition of adrenaline-mediated vasodilation. This leads to decreased erythema and softening of IHs within a few treatments $(22,23)$. During the proliferative stage of IHs, $\beta$-blockers are thought to decrease the expression of vascular endothelial growth factor (VEGF), thereby opposing aberrant angiogenesis $(23,24)$. $\beta$-blockers have been also theorized to decrease inhibition of apoptotic pathways in IHs, which may promote tumor involution $(25,26)$. Although the underlying mechanisms of $\beta$-blockers treatment are still unclear, $\beta$-blockers have currently evolved as the first-choice medicine for IHs. A previous study showed that propranolol reduced the proliferation of induced pluripotent stem cells, initiated the conversion to mesenchymal phenotype and subsequently triggered rapid IH involution (27). In this study, we found that a younger age was associated with a better RR to treatment, which was in alignment with the previous findings. However, further studies are needed for explaining the underlying mechanism of $\beta$-blockers in IH treatment.

In conclusion, this study demonstrates that treatment of IHs with oral atenolol shows high efficacy and tolerance with few adverse effects. There seem to be no differences in RRs between both $\beta$-blockers, but atenolol has the advantage of lower-dose administration and reduced number of $\beta 2$ adverse events. A randomized controlled clinical trial should be conducted to prove the equal efficacy and better tolerance of atenolol compared with propranolol. Therefore, we propose that atenolol could be added to the therapeutic arsenal for the treatment of IHs.

\section{Acknowledgments}

Funding: This study is financially supported by the grants 
of the National Natural Science Foundation of China (No. 81470755 ) and the grants of the National Natural Science Foundation of China (No. 81901021).

\section{Footnote}

Reporting Checklist: The authors have completed the STROBE reporting checklist. Available at http://dx.doi. org/10.21037/atm-20-5359

Data Sharing Statement: Available at http://dx.doi. org/10.21037/atm-20-5359

Conflicts of Interest: All authors have completed the ICMJE uniform disclosure form (available at http://dx.doi. org/10.21037/atm-20-5359). The authors have no conflicts of interest to declare.

Ethical Statement: The authors are accountable for all aspects of the work in ensuring that questions related to the accuracy or integrity of any part of the work are appropriately investigated and resolved. The study was conducted in accordance with the Declaration of Helsinki (as revised in 2013). The study was approved by Institute Review Board of Shanghai Ninth People's Hospital (SH9H2019-T272-1). Informed consent was taken from the parents or guardian of all the patients in accordance with the Declaration of Helsinki for the participation in the study, and the publication of identifiable images.

Open Access Statement: This is an Open Access article distributed in accordance with the Creative Commons Attribution-NonCommercial-NoDerivs 4.0 International License (CC BY-NC-ND 4.0), which permits the noncommercial replication and distribution of the article with the strict proviso that no changes or edits are made and the original work is properly cited (including links to both the formal publication through the relevant DOI and the license). See: https://creativecommons.org/licenses/by-nc-nd/4.0/.

\section{References}

1. Zheng JW, Zhang L, Zhou Q, et al. A practical guide to treatment of infantile hemangiomas of the head and neck. Int J Clin Exp Med 2013;6:851-60.

2. Haggstrom AN, Drolet BA, Baselga E, et al. Prospective study of infantile hemangiomas: demographic, prenatal, and perinatal characteristics. J Pediatr 2007;150:291-4.
3. Luu M, Frieden IJ. Haemangioma: clinical course, complications and management. Br J Dermatol 2013;169:20-30.

4. Greco A, D'Erme AM, Zamma Gallarati B, et al. A further experience of propranolol for severe infantile hemangiomas of the face: an observational study. Dermatol Ther 2014;27:198-202.

5. Sans V, de la Roque ED, Berge J, et al. Propranolol for severe infantile hemangiomas: follow-up report. Pediatrics 2009;124:e423-31.

6. Léauté-Labrèze C, Dumas de la Roque E, Hubiche T, et al. Propranolol for severe hemangiomas of infancy. N Engl J Med 2008;358:2649-51.

7. Painter SL, Hildebrand GD. Review of topical beta blockers as treatment for infantile hemangiomas. Surv Ophthalmol 2016;61:51-8.

8. Rouhana HF, Fruge JH, Massengale WT. Beta blocker treatment for infantile hemangiomas. Dermatol Online J 2015;21:13030/qt05k4t1hq.

9. Tasani M, Glover M, Martinez AE, et al. Atenolol treatment for infantile haemangioma. Br J Dermatol 2017;176:1400-2.

10. Ruitenberg G, Young-Afat DA, de Graaf M, et al. Ulcerated infantile haemangiomas: the effect of the selective beta-blocker atenolol on wound healing. Br J Dermatol 2016;175:1357-60.

11. Ábarzúa-Araya A, Navarrete-Dechent CP, Heusser F, et al. Atenolol versus propranolol for the treatment of infantile hemangiomas: a randomized controlled study. J Am Acad Dermatol 2014;70:1045-9.

12. Zhang L, Wu HW, Yuan $W$, et al. Propranolol therapy for infantile hemangioma: our experience. Drug Des Devel Ther 2017;11:1401-8.

13. Izadpanah A, Izadpanah A, Kanevsky J, et al. Propranolol versus corticosteroids in the treatment of infantile hemangioma: a systematic review and meta-analysis. Plast Reconstr Surg 2013;131:601-13.

14. Bayart CB, Tamburro JE, Vidimos AT, et al. Atenolol versus propranolol for treatment of infantile hemangiomas during the proliferative phase: a retrospective noninferiority study. Pediatr Dermatol 2017;34:413-21.

15. Drolet BA, Frommelt PC, Chamlin SL, et al. Initiation and use of propranolol for infantile hemangioma: report of a consensus conference. Pediatrics 2013;131:128-40.

16. de Graaf M, Raphael MF, Breugem CC, et al. Treatment of infantile haemangiomas with atenolol: comparison with a historical propranolol group. J Plast Reconstr Aesthet Surg 2013;66:1732-40. 
17. Püttgen K, Lucky A, Adams D, et al. Topical Timolol Maleate Treatment of Infantile Hemangiomas. Pediatrics 2016;138:e20160355.

18. Danarti R, Ariwibowo L, Radiono S, et al. Topical timolol maleate $0.5 \%$ for infantile hemangioma: its effectiveness compared to ultrapotent topical corticosteroids - a single-center experience of 278 cases. Dermatology 2016;232:566-71.

19. Jinnin M, Medici D, Park L, et al. Suppressed NFATdependent VEGFR1 expression and constitutive VEGFR2 signaling in infantile hemangioma. Nat Med 2008;14:1236-46.

20. Kirch W, Gorg KG. Clinical pharmacokinetics of atenolol-a review. Eur J Drug Metab Pharmacokinet 1982;7:81-91.

21. Pope E, Chakkittakandiyil A, Lara-Corrales I, et al. Expanding the therapeutic repertoire of infantile haemangiomas: cohort-blinded study of oral nadolol compared with propranolol. Br J Dermatol 2013;168:222-4.

22. Fredriksson JM, Lindquist JM, Bronnikov GE, et al. Norepinephrine induces vascular endothelial growth factor gene expression in brown adipocytes through a beta-adrenoreceptor/cAMP/protein kinase A pathway

Cite this article as: Zhao ZL, Liu C, Wang QZ, Wu HW, Zheng JW. Oral atenolol treatment for infantile hemangiomas: clinical analysis of 133 consecutive patients. Ann Transl Med 2021;9(2):116. doi: 10.21037/atm-20-5359 involving Src but independently of Erk1/2. J Biol Chem 2000;275:13802-11.

23. Munabi NC, England RW, Edwards AK, et al. Propranolol targets hemangioma stem cells via cAMP and mitogenactivated protein kinase regulation. Stem Cells Transl Med 2016;5:45-55.

24. Boscolo E, Mulliken JB, Bischoff J. VEGFR-1 mediates endothelial differentiation and formation of blood vessels in a murine model of infantile hemangioma. Am J Pathol 2011;179:2266-77.

25. Itinteang T, Brasch HD, Tan ST, et al. Expression of components of the renin-angiotensin system in proliferating infantile haemangioma may account for the propranolol-induced accelerated involution. J Plast Reconstr Aesthet Surg 2011;64:759-65.

26. Tu JB, Ma RZ, Dong Q, et al. Induction of apoptosis in infantile hemangioma endothelial cells by propranolol. Exp Ther Med 2013;6:574-8.

27. Mong EF, Akat KM, Canfield J, et al. Modulation of LIN28B/Let-7 signaling by propranolol contributes to infantile hemangioma involution. Arterioscler Thromb Vasc Biol 2018;38:1321-32. 